\title{
PENERAPAN $k$-MODES CLUSTERING DENGAN VALIDASI DUNN INDEX PADA PENGELOMPOKAN KARAKTERISTIK CALON TKI MENGGUNAKAN R-GUI
}

\author{
Hanik Malikhatin ${ }^{1 *}$, Agus Rusgiyono ${ }^{2}$, Di Asih I Maruddani ${ }^{3}$ \\ ${ }^{1,2,3}$ Departemen Statistika, Fakultas Sains dan Matematika, Universitas Diponegoro \\ *hanikmalikhatinn@gmail.com
}

\begin{abstract}
Prospective TKI workers who apply for passports at the Immigration Office Class I Non TPI Pati have countries destinations and choose different PPTKIS agencies. Therefore, the grouping of characteristics prospective TKI needed so that can be used as a reference for the government in an effort to improve the protection of TKI in destination countries and carry out stricter supervision of PPTKIS who manage TKI. The purpose of this research is to classify the characteristics of prospective TKI workers with the optimal number of clusters. The method used is k-Modes Clustering with values of $\mathrm{k}=2,3,4$, and 5 . This method can agglomerate categorical data. The optimal number of clusters can be determined using the Dunn Index. For grouping data easily, then compiled a Graphical User Interface (GUI) based application with RStudio. Based on the analysis, the optimal number of clusters is two clusters with a Dunn Index value of 0,4. Cluster 1 consists of mostly male TKI workers $(51,04 \%)$, aged $\geq 20$ years old $(91,93 \%)$, with the destination Malaysia country (47\%), and choosing PPTKIS Surya Jaya Utama Abadi (37,51\%), while cluster 2, mostly of male TKI workers $(94,10 \%)$, aged $\geq 20$ years old $(82,31 \%)$, with the destination Korea Selatan country (77,95\%), and choosing PPTKIS BNP2TKI $(99,78 \%)$.
\end{abstract}

Keywords: prospective TKI workers, cluster, k-Modes Clustering, categorical data, Dunn Index, GUI

\section{PENDAhUluan}

Calon TKI yang membuat paspor di Kantor Imigrasi Kelas I Non TPI Pati memiliki tujuan negara serta memilih lembaga PPTKIS yang berbeda-beda. Oleh karena itu, diperlukan pengelompokan karakteristik calon TKI agar dapat dijadikan referensi bagi pemerintah dalam upaya meningkatkan perlindungan TKI di negara tujuan serta melakukan pengawasan yang lebih ketat terhadap PPTKIS yang mengurus TKI. Analisis cluster menjadi pilihan peneliti untuk mengetahui bagaimana pengelompokan Calon TKI berdasarkan karakteristiknya.

Pada umumnya analisis cluster yang sering digunakan adalah analisis cluster $k$ Means. Pada penerapan metode $k$-Means Clustering ini, data yang digunakan adalah data numerik yang berbentuk angka (Ediyanto et al., 2013). Sementara data calon TKI yang membuat paspor di Kantor Imigrasi Kelas I Non TPI Pati tergolong ke dalam data berskala kategorik sehingga diperlukan metode analisis cluster yang dapat mengolah data berskala kategorik. Salah satunya yaitu metode $k$-Modes Clustering.

$k$-Modes Clustering merupakan suatu metode clustering yang dikembangkan dari metode $k$-Means Clustering, sehingga metode $k$-Modes Clustering bersifat efisien seperti metode $k$-Means Clustering namun digunakan pada data yang bersifat kategorik (Indriani dan Budiman, 2017). Dalam penentuan jumlah cluster yang optimal menggunakan metode validasi Dunn Index. Metode validasi Dunn Index ini memberikan skor terbaik untuk algoritma clustering yang menghasilkan cluster dengan kemiripan tinggi dalam suatu cluster namun kemiripan yang rendah antar cluster-cluster (Santoso et al., 2020). Dalam mempermudah pengelompokkan data, maka disusun aplikasi berbasis Graphical User Interface (GUI) dengan RStudio. 


\section{TINJAUAN PUSTAKA}

\subsection{Clustering}

Analisis cluster merupakan suatu analisis statistik yang bertujuan memisahkan objek ke dalam beberapa kelompok yang mempunyai sifat berbeda di antara kelompok satu dengan kelompok yang lain. Tujuan utama dari analisis cluster adalah mengelompokkan objek-objek berdasarkan kesamaan karakteristik di antara objek-objek tersebut. Objek bisa berupa produk (barang dan jasa), benda (tumbuhan atau lainnya), serta orang (responden, konsumen atau yang lain). Objek tersebut akan diklasifikasikan ke dalam satu atau lebih cluster (kelompok) sehingga objek-objek yang berada dalam satu cluster akan mempunyai kemiripan satu dengan yang lain (Heriyati dan Kurniatun, 2020).

Clustering data dapat menggunakan metode non-hierarchical cluster dan hierarchical cluster. Pada non-hierarchical cluster, peneliti menentukan jumlah cluster yang diinginkan terlebih dahulu. Setelah itu proses clustering dilakukan untuk mengetahui karakteristik (kemiripan) yang ada pada masing-masing cluster. Sedangkan pada metode hierarchical cluster, dilakukan clustering terhadap dua atau lebih objek yang memiliki karakteristik yang paling dekat secara terus-menerus hingga terbentuk hirarki dari yang paling mirip sampai yang paling tidak mirip (Hidayat dan Istiadah, 2011).

\section{2. -Means Clustering}

$k$-Means adalah metode clustering berbasis jarak yang membagi data ke dalam sejumlah cluster dan algoritma ini hanya bekerja pada data numerik. Algoritma $k$-Means sangat terkenal karena kemudahan dan kemampuannya untuk clustering data yang besar dan data outlier dengan sangat cepat (Wahyudi et al., 2020).

\subsection{Variabel Kategorik}

Variabel kategorik merupakan salah satu variabel yang nilainya dari sekumpulan kategori yang sering diberi label angka. Variabel kategorik mempunyai dua tipe skala pengukuran yaitu skala ordinal dan skala nominal (Nugraha, 2014).

\section{4. $k$-Modes Clustering}

$k$-Modes Clustering merupakan pendekatan nonparametrik untuk mendapatkan cluster dari data kategorik (Huang dan Ng, 2003). $k$-Modes Clustering pertama kali diperkenalkan oleh Huang (1998) sebagai suatu metode clustering yang dikembangkan dari metode $k$ Means Clustering, sehingga metode $k$-Modes Clustering bersifat efisien seperti metode $k$ Means Clustering namun digunakan pada data yang bersifat kategorik. Modifikasi yang dilakukan terhadap metode $k$-Means Clustering yaitu:

1. Jarak antara dua titik data $\mathrm{X}$ dan $\mathrm{Y}$ adalah jumlah fitur pada $\mathrm{X}$ dan $\mathrm{Y}$ yang nilainya berbeda (simple dissimilarity measure), secara formal dirumuskan seperti berikut ini:

$d_{1}(X, Y)=\sum_{j=1}^{m} \delta\left(x_{j}, y_{j}\right)$

dengan

$\delta\left(x_{j}, y_{j}\right)=\left\{\begin{array}{cc}0 & \left(x_{j}=y_{j}\right) \\ 1 & \left(x_{j} \neq y_{j}\right)\end{array}\right.$

$\mathrm{x}_{\mathrm{j}}$ dan $\mathrm{y}_{\mathrm{j}}$ adalah nilai fitur ke-j dari data $\mathrm{X}$ dan $\mathrm{Y}$, serta $\mathrm{m}$ adalah jumlah fitur.

2. Mengubah rata-rata (means) menjadi modus (modes).

3. Menggunakan frekuensi untuk mencari modus dalam proses pembentukan centroid. 
berikut:

Langkah-langkah k-Modes Clustering berdasarkan (Huang, 2008) adalah sebagai

1. Menentukan $\mathrm{k}$ cluster dari data dan melakukan inisialisasi cluster secara acak.

2. Mengalokasikan objek data pada cluster terdekat berdasarkan simple dissimilarity measure. Update tiap modus cluster setelah tiap alokasi.

3. Setelah semua objek data dialokasikan ke suatu cluster, memeriksa kembali nilai dissimilarity tiap objek terhadap modus. Jika suatu objek data memiliki modus terdekat berada pada cluster lain, maka memindahkan objek ke cluster yang sesuai dan update modus kedua cluster.

4. Mengulangi langkah 3 sampai tidak ada objek data yang berubah cluster (Indriani dan Budiman, 2017).

\subsection{Dunn Index}

Dunn Index merupakan salah satu metode validasi cluster. Metode ini memberikan skor terbaik untuk algoritma clustering yang menghasilkan cluster dengan kemiripan tinggi dalam suatu cluster namun kemiripan yang rendah antar cluster-cluster. Dunn Index bertujuan untuk mengidentifikasi cluster yang terpisah dengan baik. Metode ini menghitung rasio jarak antar cluster minimal dengan jarak intra-cluster maksimal. Dengan demikian semakin tinggi nilai Dunn Index, maka semakin optimal jumlah cluster yang dihasilkan. Menurut Ansari (2011), Dunn Index dirumuskan sebagai berikut:

$D=\left\{\frac{\min _{\substack{1 \leq i \leq k \\ i+1 \leq j \leq q}}\left(d\left(C_{i}, C_{j}\right)\right)}{\max _{1 \leq l \leq q} d\left(C_{l}\right)}\right\}$

dengan

$d\left(C_{i}, C_{j}\right)$ : ukuran kedekatan antara cluster $i$ dan cluster $j$.

$d\left(C_{l}\right)$ : ukuran kedekatan antar anggota dalam cluster $l$ (Pratiwi et al., 2019).

\subsection{RStudio dan Graphical User Interface (GUI)}

RStudio merupakan tool pemrograman atau integrated development environment (IDE) bahasa R yang memiliki antarmuka lebih baik daripada RGui (Faisal dan Nugrahadi, 2019).

RStudio dapat digunakan untuk pengolahan metode k-Modes Clustering dan Dunn Index. Pada pengolahan $k$-Modes Clustering, diperlukan sintaks RStudio sebagai berikut: kmodes(data, modes, iter $\max =10$, weighted $=$ FALSE, fast $=$ TRUE) (https://www.rdocumentation.org).

Sedangkan pada pengolahan Dunn Index, diperlukan sintaks RStudio sebagai berikut: dunn(distance $=$ NULL, clusters, Data $=$ NULL, method = "euclidean") (https://www.rdocumentation.org).

Graphical User Interface (GUI) adalah tampilan grafis yang memudahkan user atau pengguna berinteraksi dengan perintah teks (Chapman, 2001 dalam Kurniastuti dan Andini, 2018). Packages utama yang dibutuhkan dalam pembuatan GUI salah satunya adalah shiny yang terdiri dari 3 komponen yaitu User Interface (ui), Server, dan ShinyApp (https://medium.com). 


\section{METODE PENELITIAN}

\subsection{Sumber Data, Variabel Penelitian, dan Alat Analisis}

Data yang digunakan dalam penelitian tugas akhir ini adalah data sekunder yang diperoleh dari hasil rekapan Bidang Informasi dan Komunikasi Keimigrasian Kantor Imigrasi Kelas I Non TPI Pati. Data tersebut merupakan data pemohon paspor calon TKI pada tahun 2019 di daerah kerja utama yang meliputi Kabupaten Pati, Kabupaten Rembang, Kabupaten Blora, dan Kabupaten Jepara.

Variabel yang digunakan disajikan dalam tabel 1 sebagai berikut:

\begin{tabular}{cc} 
& Tabel 1. Variabel Penelitian \\
\hline Variabel & Nama Variabel \\
\hline $\mathrm{X}_{1}$ & Jenis Kelamin \\
$\mathrm{X}_{2}$ & Umur \\
$\mathrm{X}_{3}$ & Negara yang Dituju Calon TKI \\
$\mathrm{X}_{4}$ & PPTKIS (Pelaksana Penempatan Tenaga Kerja Indonesia Swasta) \\
& yang Mengurus Calon TKI \\
\hline
\end{tabular}

Data penelitian diolah menggunakan software Microsoft Excel 2010 dan RStudio 1.0.153.

\subsection{Metode Analisis}

Langkah-langkah analisis data yang akan dilakukan adalah sebagai berikut:

1. Melakukan pre-processing dan pelabelan data.

2. Melakukan transformasi data ke dalam bentuk data biner.

3. Menyusun User Interface dan Server pada GUI.

4. Running Program GUI.

5. Memasukkan data.

6. Menentukan nilai $k$ (jumlah cluster) yaitu $k=2,3,4$, dan 5 .

7. Melakukan $k$-Modes Clustering.

8. Melakukan validasi Dunn Index1.

9. Memilih $k$ optimal.

10. Melakukan profiling hasil $k$-Modes Clustering dengan $k$ optimal.

\section{HASIL DAN PEMBAHASAN}

\subsection{Pembuatan Graphical User Interface (GUI)}

Program GUI yang dibangun dalam penelitian ini terdiri dari beberapa bagian yaitu: halaman judul, input data $k$-Modes Clustering, input data Dunn Index, hasil $k$-Modes Clustering, hasil Dunn Index, dan hasil Profiling Cluster. Packages utama yang dibutuhkan dalam pembuatan GUI pada penelitian ini adalah shiny yang terdiri dari 3 komponen yaitu User Interface (ui), Server, dan ShinyApp. Setelah kedua fungsi pada paket shiny yaitu ui dan server disatukan dengan perintah ShinyApp(ui,server), maka dapat dijalankan melalui jendela RStudio dengan mengklik tombol Run App dan menghasilkan tampilan GUI pada Gambar 1. 


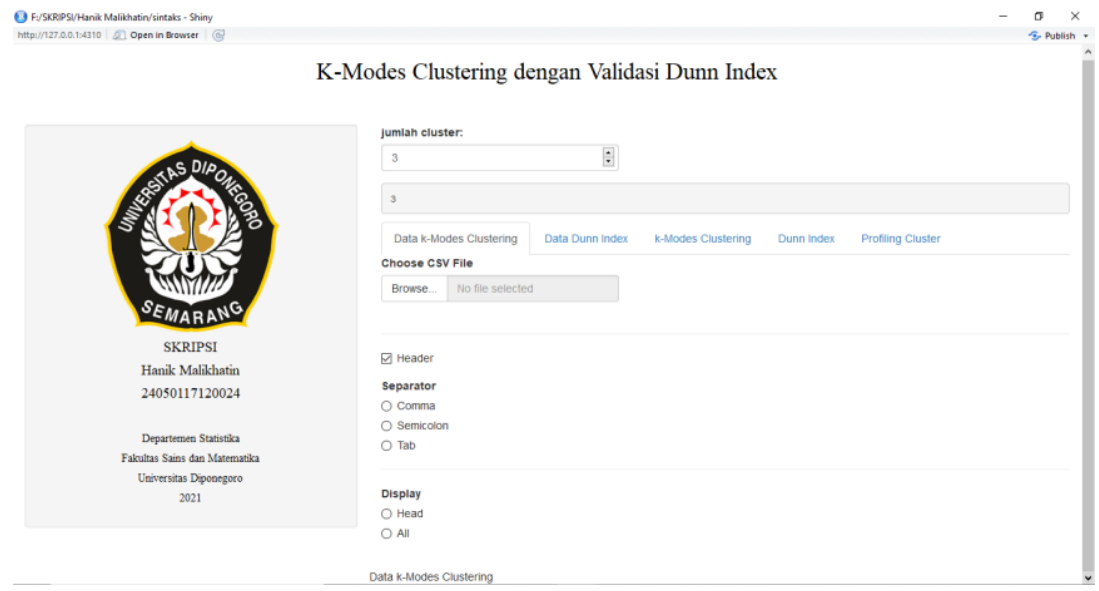

Gambar 1. Tampilan Awal GUI

Pengelompokan data menggunakan $k$-Modes Clustering dengan validasi Dunn Index dapat dijalankan dengan memilih data melalui mengklik tombol Browse pada bagian Data $k$-Modes Clustering dan Data Dunn Index serta memilih jumlah cluster sesuai keinginan.

\subsection{Analisis $k$-Modes Clustering}

Pada proses clustering menggunakan metode $k$-Modes Clustering dilakukan pada berbagai nilai $k(k=2,3,4$, dan 5$)$.

Hasil $k$-Modes Clustering dengan $k=2$ ditampilkan pada gambar 2.

\section{Hasil $k$-Modes Clustering dengan $k=2$}

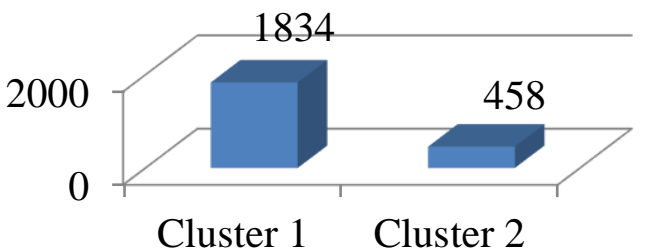

Gambar 2. Histogram Frekuensi Hasil $k$-Modes Clustering dengan $k=2$

Pada gambar 2 terlihat bahwa anggota cluster 1 sebanyak 1.834 orang dan anggota cluster 2 sebanyak 458 orang.

Pada $k=3$, ditampilkan pada gambar 3 .

\section{Hasil $k$-Modes Clustering dengan $k=3$}

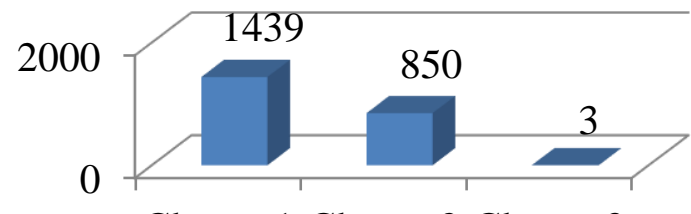

Cluster 1 Cluster 2 Cluster 3

Gambar 3. Histogram Frekuensi Hasil $k$-Modes Clustering dengan $k=3$

Pada gambar 3 terlihat bahwa anggota cluster 1 sebanyak 1.439 orang, anggota cluster 2 sebanyak 850 orang, dan anggota cluster 3 sebanyak 3 orang. 
Pada $k=4$, ditampilkan pada gambar 4 .

\section{Hasil $k$-Modes Clustering dengan $k=4$}

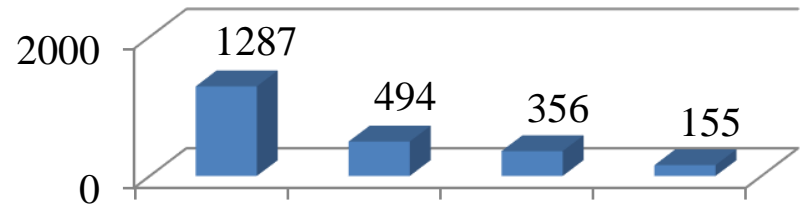

Cluster 1 Cluster 2 Cluster 3 Cluster 4

Gambar 4. Histogram Frekuensi Hasil $k$-Modes Clustering dengan $k=4$

Pada gambar 4 terlihat bahwa anggota cluster 1 sebanyak 1.287 orang, anggota cluster 2 sebanyak 494 orang, anggota cluster 3 sebanyak 356 orang, dan anggota cluster 4 sebanyak 155 orang.

Pada $k=5$, ditampilkan pada gambar 5 .

\section{Hasil $k$-Modes Clustering dengan $k=5$}

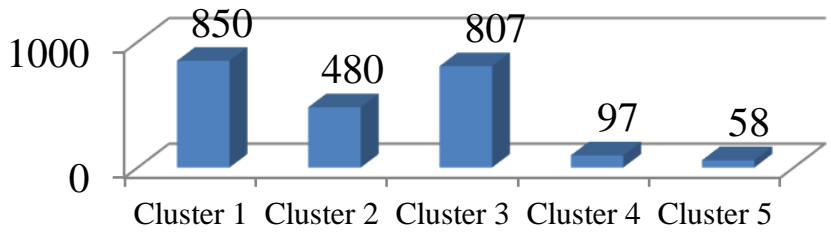

Gambar 5. Histogram Frekuensi Hasil $k$-Modes Clustering dengan $k=5$

Pada gambar 5 terlihat bahwa anggota cluster 1 sebanyak 850 orang, anggota cluster 2 sebanyak 480 orang, anggota cluster 3 sebanyak 807 orang, anggota cluster 4 sebanyak 97 orang, dan anggota cluster 5 sebanyak 58 orang.

\subsection{Dunn Index}

Berdasarkan hasil olahan RStudio, diperoleh hasil pada tabel 2.

\begin{tabular}{cc} 
Tabel 2. Tabel Nilai Dunn Index \\
\hline$k$ & Nilai Dunn Index \\
\hline 2 & 0,4 \\
3 & 0 \\
4 & 0 \\
5 & 0 \\
\hline
\end{tabular}

Berdasarkan tabel 6 dapat disimpulkan bahwa cluster dengan $k=2$ lebih optimal dibandingkan cluster dengan $k=3,4$, dan 5. Hal ini dikarenakan nilai Dunn Index pada cluster dengan $k=2$ paling besar dibandingkan yang lainnya.

\subsection{Profiling Cluster dengan $k$ optimal $(k=2)$}

Hasil pengolahan metode $k$-Modes Clustering dengan $\mathrm{k}=2$ menggunakan RStudio diperoleh jumlah cluster 1 sebanyak 1.834 orang calon TKI dan cluster 2 sebanyak 458 orang calon TKI.

Berdasarkan hasil olahan RStudio pada profiling cluster 1, contoh datanya ditampilkan pada tabel 3.

Tabel 3. Tabel Anggota Cluster 1 dengan $k=2$

\begin{tabular}{llllll}
\hline No & Nama & X1 & X2 & X3 & X4 \\
\hline 1 & Sutiyah & 2 & 2 & 13 & 9 \\
2 & Febri Puguh Trisnani & 2 & 2 & 13 & 9
\end{tabular}




\begin{tabular}{llllll}
3 & Zubaidah & 2 & 2 & 13 & 33 \\
4 & Tri Enggar Budiarti & 2 & 2 & 13 & 33 \\
5 & Ahmad Jauhari & 1 & 2 & 13 & 43 \\
6 & Lestari & 2 & 2 & 13 & 28 \\
7 & Ruhyani & 2 & 2 & 13 & 28 \\
8 & Nur Akimil Laela & 2 & 2 & 5 & 28 \\
9 & Asmini & 2 & 2 & 5 & 28 \\
10 & Lutfi Fitriani & 2 & 2 & 13 & 28 \\
. &. & $\cdot$ &. &. &. \\
. & . & $\cdot$ &. &. &. \\
1830 & Dicky Prasetyo Aji & 1 & 2 & 13 & 43 \\
1831 & Dandang Handoko & 1 & 2 & 13 & 43 \\
1832 & Surini & 2 & 2 & 12 & 7 \\
1833 & Suharti Bt Sukarjo Karyono & 2 & 2 & 12 & 9 \\
1834 & Leginah & 2 & 2 & 12 & 7 \\
\hline
\end{tabular}

Kemudian mencari frekuensi masing-masing variabel pada profiling cluster 1 . Setelah dicari frekuensinya, dapat disimpulkan bahwa cluster 1 sebagian besar terdiri dari calon TKI yang berjenis kelamin laki-laki, berumur $\geq 20$ tahun, dengan negara yang dituju Negara Malaysia dan memilih PPTKIS Surya Jaya Utama Abadi.

Sedangkan pada profiling cluster 2, contoh datanya ditampilkan pada tabel 4. Tabel 4. Tabel Anggota Cluster 2 dengan $k=2$

\begin{tabular}{llllll}
\hline No & Nama & X1 & X2 & X3 & X4 \\
\hline 1 & Haryanto & 1 & 2 & 7 & 8 \\
2 & Suparti & 2 & 2 & 7 & 8 \\
3 & Ahmad Rokhimul Ibad & 1 & 1 & 6 & 8 \\
4 & Ipung Supriyanto & 1 & 2 & 6 & 8 \\
5 & Mohamad Abdul Rohman & 1 & 2 & 6 & 8 \\
6 & Okik Setiyawan & 1 & 2 & 6 & 8 \\
7 & Pariyono & 1 & 2 & 13 & 8 \\
8 & Mohammad Junaedi & 1 & 2 & 6 & 8 \\
9 & Prehatin & 1 & 1 & 6 & 8 \\
10 & Dewi Purwati & 2 & 2 & 6 & 8 \\
. & . & $\cdot$ & $\cdot$ &. &. \\
. & . & $\cdot$ &. &. &. \\
454 & Yeni Husada & 1 & 2 & 7 & 8 \\
455 & Bambang Sugiyanto & 1 & 1 & 7 & 8 \\
456 & Muhammad Ridwan & 1 & 2 & 7 & 8 \\
457 & Adi Kuncoro & 1 & 2 & 7 & 8 \\
458 & Ahmad Rusdiono & 1 & 2 & 7 & 8 \\
\hline
\end{tabular}

Kemudian mencari frekuensi masing-masing variabel pada profiling cluster 2. Setelah dicari frekuensinya, dapat disimpulkan bahwa cluster 2 sebagian besar terdiri dari calon TKI yang berjenis kelamin laki-laki, berumur $\geq 20$ tahun, dengan negara yang dituju Negara Korea Selatan dan memilih PPTKIS BNP2TKI.

\section{KESIMPULAN}

Setelah dilakukan analisis cluster menggunakan metode $k$-Modes Clustering dan Dunn Index pada 2.292 pemohon paspor calon TKI pada tahun 2019 di daerah kerja utama, dapat disimpulkan bahwa Graphycal User Interface (GUI) dapat mempermudah pengguna untuk melakukan komputasi k-Modes Clustering dengan validasi Dunn Index menggunakan jumlah cluster sesuai keingingan. Hasil dari k-Modes Clustering dengan Validasi Dunn Index terbentuk dua cluster dengan banyaknya cluster 1 sebanyak 1.834 orang dan cluster 2 sebanyak 458 orang. Jumlah cluster terbaik yang dihasilkan menggunakan metode $k$ Modes Clustering adalah dua cluster $(k=2)$ dengan memiliki nilai Dunn Index paling 
besar yaitu 0,4. Pada cluster 1 paling banyak terdiri dari calon TKI yang berjenis kelamin laki-laki (51,04\%), berumur $\geq 20$ tahun (91,93\%), dengan negara yang dituju Malaysia (47\%), dan memilih PPTKIS Surya Jaya Utama Abadi (37,51\%), sedangkan cluster 2 paling banyak terdiri dari calon TKI yang berjenis kelamin laki-laki $(94,10 \%)$, berumur $\geq$ 20 tahun $(82,31 \%)$, dengan negara yang dituju Korea Selatan $(77,95 \%)$, dan memilih PPTKIS BNP2TKI $(99,78 \%)$.

\section{DAFTAR PUSTAKA}

DataCamp. -. kmodes: K-Modes Clustering. Tersedia: https://www.rdocumentation. org/packages/klaR/versions/0.6-15/topics/kmodes (diakses pada tanggal 6 April 2021).

DataCamp. -. dunn: Dunn Index. Tersedia: https://www.rdocumentation.org/ packages/clValid/versions/0.6-9/topics/dunn (diakses pada tanggal 7 April 2021).

Ediyanto, Mara, M. N. dan Satyahadewi, N. 2013. Pengklasifikasian Karakteristik Dengan Metode K-Means Cluster Analysis. Buletin Ilmiah Mat. Stat. dan Terapannya (Bimaster) Vol. 02, No. 2, Hal: 133-136.

Faisal, M. R. dan Nugrahadi D. T. 2019. Belajar Data Science Klasifikasi dengan Bahasa Pemrograman R. Kalimantan Selatan: Scripta Cendekia.

Hakim, R. B. F. 2019. Bermain dengan $R$ Shiny. Tersedia: https://medium.com/ @ 986110101/bermain-dengan-r-shiny-b3430fc7ae5f (diakses pada tanggal 19 Juli 2021).

Heriyati, P. dan Kurniatun, T. C. 2020. Analisa Triple Helix pada Industri Fashion di Jakarta. Pasuruan: Qiara Media.

Hidayat, T. dan Istiadah, N. 2011. Panduan Lengkap Menguasai SPSS 19 untuk Mengolah Data Statistik Penelitian. Jakarta Selatan: MediaKita.

Huang, Z. dan Ng, M. K. 2003. A Note on K-modes Clustering. Journal of Classification Vol. 20, No. 2, Hal: 257-261.

Indriani, F. dan Budiman, I. 2017. K-Modes Clustering untuk Mengetahui Jenis Masakan Daerah yang Populer pada Website Resep Online (Studi Kasus: Masakan Banjar di cookpad.com. Jurnal Teknologi Informasi dan Ilmu Komputer Vol. 4, No. 4, Hal: 290-296.

Kurniastuti dan Andini. 2018. Perancangan Program Penentuan Histogram Citra dengan Graphical User Interface (GUI). Applied Technology and Computing Science Journal Vol. 1, No. 1, Hal:-.

Nugraha, J. 2014. Pengantar Analisis Data Kategorik: Metode dan Aplikasi Menggunakan Program R. Yogyakarta: Deepublish.

Pratiwi, S. I., Widiharih, T. dan Hakim, A. R. 2019. Analisis Klaster Metode Ward dan Average Linkage dengan Validasi Dunn Index dan Koefisien Korelasi Cophenetic (Studi Kasus: Kecelakaan Lalu Lintas Berdasarkan Jenis Kendaraan Tiap Kabupaten/Kota di Jawa Tengah Tahun 2018). Jurnal Gaussian Vol. 8, No. 4, Hal: 486-495.

Santoso, B., Azis, A. I. S. dan Zohrahayaty. 2020. Machine Learning \& Reasoning Fuzzy Logic Algoritma, Manual, Matlab, \& Rapid Miner. Yogyakarta: Deepublish.

Wahyudi, M., Masitha, M., Saragih, R. dan Solikhun, S. 2020. Data Mining: Penerapan Algoritma K-Means Clustering dan K-Medoids Clustering. Medan: Yayasan Kita Menulis. 